\title{
Overview of the Prevalence and Associated Risk, Factors of Lifestyle Diseases in University Students
}

\author{
Damar Nagheer, Rachael Irving, Novie Younger-Coleman \\ Department of Medical Sciences, Biochemistry Section, The University of the West Indies Mona Campus, Mona, Jamaica \\ Email: damarnagheer@gmail.com, damar.nagheer@mymona.edu.jm
}

How to cite this paper: Nagheer, D., Irving, R. and Younger-Coleman, N. (2017) Overview of the Prevalence and Associated Risk, Factors of Lifestyle Diseases in University Students. International Journal of Clinical Medicine, 8, 344-352.

https://doi.org/10.4236/ijcm.2017.85032

Received: March 8, 2017

Accepted: May 28, 2017

Published: May 31, 2017

Copyright $\odot 2017$ by authors and Scientific Research Publishing Inc. This work is licensed under the Creative Commons Attribution International License (CC BY 4.0).

http://creativecommons.org/licenses/by/4.0/

\begin{abstract}
Background: The prevalence of lifestyle diseases is increasing rapidly in Youths (17 - 25 yrs). Factors such as poor diet, little or no physical exercise, and smoking are major contributors to this increase. Lifestyle diseases in youths present a timeline challenge as disease duration is longer and financial burden more costly. Aim: To analyse and synthesize published literature on the prevalence of and risk factors associated with four lifestyle diseases-obesity, hypertension, diabetes and cancer-in university/college students worldwide. Results: The literature indicates that among lifestyle diseases in university/college students, overweight/obesity (Body Mass Index $>25 \mathrm{~kg} / \mathrm{m}^{2}$ ) had the highest prevalence of $45.6 \%$ and duration of approximately 5 years. Cardiovascular diseases and hypertension had lower prevalence rates but prehypertension which lingers $>4$ years was at $32.0 \%$. Type 1 diabetes mellitus (T1DM) had a fairly high prevalence in college students (21.7\%); type 2 diabetes mellitus (T2DM) was found in much lower percentage (12.95\%). Cancer had the lowest prevalence of $>2 \%$ but was increasing in most regions based on the presence of multiple risk factors. Conclusion: Increase prevalence of these diseases in youths indicates that young people are at high risk of developing these diseases due to poor early lifestyle habits. Early corrective measures can reduce the burden of many lifestyle diseases.
\end{abstract}

\section{Keywords}

DM1 (Diabetes Mellitus Type 1), DM2 (Diabetes Mellitus Type 2), WHR (Waist-Hip Ratio), Obesity, World Health Organization (WHO)

\section{Introduction}

The overview will look at the percentage prevalence of four major diseases-obesity/overweight, hypertension, diabetes and cancer in university/college stu- 
dents. The review will look at percentage prevalence across different regions worldwide including: Africa, Europe, Asia, and South America, the United States and the Caribbean. Results will include both an individual percentage for different universities in each region and also an average percentage prevalence for each disease. The targeted population is university students which are usually between the ages of 17 - 30 years. Each year there is an increase in percentage prevalence for lifestyle diseases due to continued bad lifestyle habits such as poor diet and lack of exercise. The overview will give a general idea of what current statistics are in relation to the four lifestyle diseases outline and the progression of each.

A lifestyle disease is defined as a non-communicable disease that is developed from unhealthy lifestyle choices that are related to smoking, alcohol, drugs and exercise. Lifestyle diseases include but are not limited to diabetes, obesity, cardiovascular diseases and some forms of cancers [1]. According to the WHO non-communicable diseases (NCD) account for over 36 million deaths each year. NCD deaths include cardiovascular diseases (17.3 million), cancers (7.6 million) and diabetes (1.3 million), all of which are categorized as lifestyle diseases [1].

Alwan indicated that lifestyle diseases are responsible for $63 \%$ of deaths globally as at 2008 with 80 percent of deaths taking place in low and middle-income countries [2] [3]. Among these lifestyle diseases, obesity, diabetes and cardiovascular diseases are major contributors to death.

Obesity and overweight are defined by WHO as abnormal or excessive fat accumulation that may impair health [4]. Body mass index (BMI) is used as an indicator for determining Obesity. BMI uses a ratio of weight and height measurement and is defined by a person's weight in kilograms divided by the square of height in meters $\left(\mathrm{kg} / \mathrm{m}^{2}\right)$. According to WHO, a BMI greater than or equal to 30 is considered as obesity while overweight is greater than or equal to 25 [4].

WHO defines cardiovascular diseases as any disorders of the heart and blood vessels, which includes, rheumatic heart disease, cerebrovascular disease (stroke), raised blood pressure (hypertension), peripheral artery disease, coronary heart disease (heart attacks), congenital heart disease and heart failure. Tobacco use, physical inactivity, an unhealthy diet and harmful use of alcohol are proposed to be the major causes which are all lifestyle related [5].

Another lifestyle related NCD is Diabetes which is defined by WHO as a chronic disease, which occurs when the pancreas does not produce enough insulin, or when the body cannot effectively use the insulin it produces causing an increase in the concentration of glucose in the blood (hyperglycaemia).

Three main types of diabetes exist:

Type 1 diabetes (previously known as insulin-dependent or childhood-onset diabetes) is described as a lack of insulin being produced. Type 2 diabetes (formerly called non-insulin-dependent or adult-onset diabetes) occurs as a result of the body not being able to effectively use the insulin it produces. Excess body weight and physical inactivity are usually the major causes for its development. 
Gestational diabetes, the third type, is characterized by hyperglycaemia in pregnancy [6].

However, only two types: Type 1 and Type 2 diabetes mellitus will be considered for this review.

\section{Method}

\section{SCREENING}

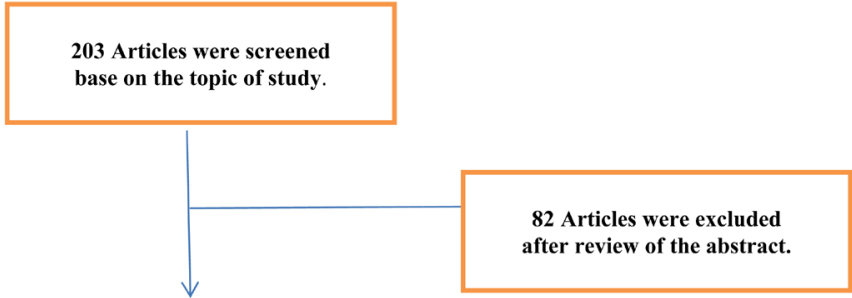

SUITABILITY

15 Articles were eligible for the study based on full text review criteria.

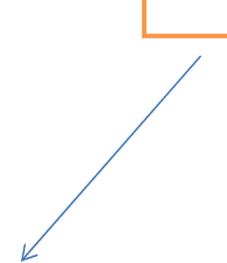

INCLUSION

23 Articles were included based on specific review criteria.
EXCLUSION

93 Articles were excluded base on there relevance and specificity to the review.

\section{Prevalence of Lifestyle Diseases}

Prevalence of lifestyle diseases is rapidly increasing worldwide and according to the World Health Organization (WHO), non-communicable diseases are now the leading cause of death around the world (2011). NCDs of high significance include cardiovascular diseases, obesity and diabetes. The rise in prevalence of lifestyle diseases is due to tobacco use, poor diet and harmful use of alcohol [7].

\subsection{Cardiovascular Diseases}

Of NCDs cardiovascular diseases account for the most deaths with 17.3 million people dying annually [1]. In a study on university students in Sao Paulo, Brazil, risk of developing cardiovascular diseases was characterized mainly by a family history of the disease. There was $44.6 \%$ prevalence in such case while smoking and physical activities showed less prevalence; $10.7 \%$ and $35.7 \%$ respectively. Also lipid levels which gives an indication of development of cardiovascular disease showed prevalence in high total cholesterol and LDL-c levels as $16.1 \%$ and $5.4 \%$ respectively, while decreased HDL-c levels and increased triglyceride levels both showing $8.9 \%$ prevalence [8]. 
Similar study at the University of Talca, Chile showed a $12.8 \%$ prevalence of some degree of arterial hypertension among student which showed greater severity in men. Physical activity was much less in Chile with $91.5 \%$ of student not participating in any major physical activity while there was a much greater percentage of smokers (39.8\%). Hypercholesterolemia was also seen in students with a $20.2 \%$ prevalence. $35.2 \%$ had cholesterol concentration of $200-210 \mathrm{mg} / \mathrm{dl}$ and $40.9 \%$ had concentrations of $221-230$ or greater [9].

Hypertension In a study done on college students at the University of New Hampshire as much as $60 \%$ of males had high blood pressure/hypertensive [10]. However, lower incidence was seen in a descriptive study on undergraduate students in Lubango-Angola. Hypertension had a much lower prevalence among students with a $26.7 \%$ prevalence [11].

Further research done on both prehypertension and hypertension in college students in Kuwait defined prehypertension as systolic pressure between 120 and $139 \mathrm{~mm} \mathrm{Hg}$ or diastolic pressure between 80 and $89 \mathrm{~mm} \mathrm{Hg}$. Results showed that none of the subjects were hypotensive. Of the participants $39.5 \%$ were prehypertensive and 7\% were considered hypertensive. Other tests were done simultaneously including lipid test and an oral glucose tolerance test. Finding showed a linkage between BMI determined Obesity, high HDL and cholesterol level; all of which are lifestyle dependent [12].

\subsection{Obesity/Overweight}

Overweight and Obesity is a growing trend in students and adults across the world. Poor diet and exercise being the most significant contributing factors. In a study in Sao Paulo on first year university students, research shows that the prevalence of overweight and obesity was as high as $17.8 \%$ and $7.1 \%$, respectively. Additional data showed that individuals consumed an inadequate diet which was high in fat and protein but low in dietary fibre and carbohydrates. Consumption of a high quantity of fat among students is indicative of the percentage overweight and obesity found in the study [8]. An even higher percentage of overweight and obesity was seen in a study on university students in south central Chile. Results show a prevalence of $45.5 \%$ in men and $24.3 \%$ in women. In men the percentage represents almost half of the sample size. A reason for this was that most of the men sampled was involved in a little or no physical activities or had poor diets. Also measurement of WHR using $>102 \mathrm{~cm}$ for men and $>88 \mathrm{~cm}$ for women as the cut-off point it was seen that $12.8 \%$ of both males and females had a value greater than the normal [9].

One method that is commonly used to determine Obesity is the Body Mass Index (BMI). This method was used in a study on obesity among male university students in the United Arab Emirates. Non-obese students were classified as students with a cut-off of $<25$ while obese students were $\geq 25$. The prevalence of obesity in male students was $35.7 \%$. There was a relative risk (RR) of 1.88 for students who had a family history of obesity/overweight or one of the other three lifestyle diseases. Relative risk was also seen in smokers and persons not 
practicing sports. However, a family history was the only statistically significant risk factor [13].

Similarly, Iran University of Medical Sciences used the BMI bivariate analysis. For this study, BMI was used to classify persons as non-obese (BMI less than 25 $\left.\mathrm{kg} / \mathrm{m}^{2}\right)$ and as obese $\left(B M I \geq 25 \mathrm{~kg} / \mathrm{m}^{2}\right)$. Mean BMI for all subjects was $21.7+/-$ $2.9 \mathrm{~kg} / \mathrm{m}^{2}$. Almost $88 \%$ of the subjects were classified into a non-obese group $\left(\mathrm{BMI}<25 \mathrm{~kg} / \mathrm{m}^{2}\right)$. About $10 \%$ were underweight and $12.4 \%$ of the students had a BMI more than $25 \mathrm{~kg} / \mathrm{m}^{2}$ ). The sample therefore shows that most individuals were considered as non-obese since the mean BMI was in the normal range [14]. In contrast, Stack et al. had an average BMI that would be considered in the overweight category having an average BMI of $26.81 \pm 0.75 \mathrm{~kg} / \mathrm{m}^{2}$ but the population studied was not overweight [15].

Further research classified obesity into grade 1 and 2 (BMI $>25$ and $>30$ $\mathrm{kg} / \mathrm{m}^{2}$ ). Prevalence of grade 1 and 2 obesity was found to be 32.0 and $8.9 \%$, respectively. Factors that were found to be significantly associated with obesity included gender, age, marital status, obesity among parents, dieting, last physical check-up, year of study, regular meals eaten and high school GPA [16].

Research by Huang et al. used similar criteria (BMI $>25$ and $>30$ to classify obesity). The results showed overweight prevalence of $21.6 \%$ using BMI directly and $16.2 \%$ using BMI percentile while obesity prevalence was $4.2 \%$ using BMI percentile and $4.9 \%$ using BMI directly. It was seen that assessment using direct BMI measurement gave higher percentage of both overweight and obesity. The BMI percentile uses comparison between other individuals in the sample and therefore gives a better indication of obesity prevalence [17].

Study on more than 800 college students at the University of New Hampshire in a general nutrition course found that approximately one-third (1/3) of the sample size was either overweight or obese. The results also included metabolic syndrome which is a cluster of five risk factors (low HDL, excess abdominal fat, high triglycerides, high blood pressure and high blood glucose). In males prevalence of metabolic syndrome was as much as sixty-six percent and fifty percent in females for having at least one of the risk factors. Eight percent of males had all five [10].

Another research surveyed 738 college students aged 18 to 27 years to assess overweight, obesity, dietary habits, and physical activity. They used BMI (body mass index) $>25 \mathrm{~kg} / \mathrm{m}^{2}$ or BMI $>85$ th percentile and BMI $>30 \mathrm{~kg} / \mathrm{m}^{2}$ or BMI $>$ 95th percentile to estimate overweight and obesity in those aged $<19$ years. To define overweight and obesity in those $>20$ years, they used BMI $>25 \mathrm{~kg} / \mathrm{m}^{2}$ and $>30 \mathrm{~kg} / \mathrm{m}^{2}$. They found overweight rates of $21.6 \%$ using BMI directly and $16.2 \%$ using BMI percentile and obesity rates of $4.9 \%$ using BMI directly and $4.2 \%$ using BMI percentile. More than $69 \%$ of the participants reported consuming $<5$ servings of fruits and vegetables per day and more than $67 \%$ reported consuming $<20 \mathrm{~g}$ of fibre per day. Also of significance participants reported physical activity on fewer than 3 days per week. Most college students were not meeting the required diet and physical activity levels. 


\subsection{Diabetes}

Diabetes is usually in the form of Type 1 in Youths, however few cases of Type 2 exists. In college students the prevalence of diabetes varies based on sex, socioeconomic and socio-demographic factors. Study on a group of college students in south Texas shows high prevalence of diabetes or at risk of developing diabetes, $21.7 \%$ of subject showed elevated reported risk while $4.3 \%$ of subjects had a moderate-to-high risk of developing diabetes [15]. Much lower percentage of Type 2 diabetes was seen in another study on 702 students in Fortaleza, Brazil. $10.2 \%$ of males and $15.7 \%$ of females had high glucose levels. $13.8 \%$ of subjects between ages 16 - 19 had elevated levels which decreased in ages 20 - 24 (11.9\%) and 25 - 28 (10.7) [11].

On the other hand, a study in south India on a group of over 3000 students between ages 5 - 19 using oral glucose tolerance test found that there was no case of diabetes of any kind despite $8.6 \%$ of subjects having a family history of the disease [18].

\subsection{Cancer}

Although there is not much research done on prevalence of cancer in children or youths research shows increasing risk of developing cancer due to lifestyle choices. Research on Northwest University students showed that a large percentage of the subjects were not eating the required amount of fruits and vegetables (95\%) while 60\% were not getting enough physical activities; two risk factors that increase risk of developing the disease [19]. Study also found a relationship between obesity and cancer. In women, $20 \%$ of cancer-associated deaths were caused by obesity. In one such case overweight or obesity can increase the chance of getting breast cancer by creating a cancer-friendly environment through fat cells [19].

\subsection{Significance of the Findings}

The four lifestyle diseases varied in prevalence in university/ college students. Obesity and overweight was the most common lifestyle disease found in youth. Percentages of overweight were generally much higher than obesity. However, lack of exercise, poor diet and other bad health practices on a regular basis can cause overweight individuals to become obese. High percentages of overweight $(45.5 \%)$ increase the chance of more individuals becoming obese with time. Of note, males studied showed greater prevalence than females due to the fact they were also less physical and were more involved in alcohol consumption and smoking. In all cases of overweight and obesity there was trend of WHR values being over the normal $(>102 \mathrm{~cm}$ for males and $>88 \mathrm{~cm}$ for females, as much as over $12 \%$ in some cases. Type 1 diabetes also had high prevalence in college students but lower prevalence in comparison to overweight and obesity. Type 2 diabetes had similar prevalence as type 1 diabetes. However, it is expected that type 2 diabetes would have very low percentage since it is uncommon in the age group but a family history of the disease and bad health practices gives reason for such findings. In contrast to overweight and obesity females had higher per- 
centages as well as a study found no incidence of diabetes in one case. Hypertension generally had lower prevalence than obesity in most cases but higher prevalence than type 1 or type 2 diabetes. However, one study found as much as $60 \%$ of males having hypertension. Pre-hypertension was found in high percentage (up to $39.5 \%$ ), subjects which were pre-hypertensive had bad lifestyle choices which may result in hypertension with time. Cancer prevalence in college/university students is not as high as the other three lifestyle related diseases but research shows increasing risk of students developing cancer due to poor diet and lack of exercise. Both can also cause individuals to become overweight or obesity which is link to cancer especially in women.

\section{Conclusion}

In most of the studies done on college/university one or more lifestyle diseases were found in the sample. Obesity and overweight was the most prevalent with consistently high percentage in each study. Similarly hypertension and pre-hypertension showed high prevalence while diabetes have low prevalence in comparison. Cancer was not prevalent but shows high risk of development in students. Finding indicates the need for interventions in developing strategies which targets bad lifestyle choices and therefore reducing the risk of developing such diseases.

Showing the average estimated percentage prevalence of cancer and three other lifestyle diseases across four regions.

\begin{tabular}{llllll}
\hline Diseases & North America & Europe & Asia & Africa & Caribbean \\
\hline Cancer & $2.3 \%[22]$ & $2.45 \%[22]$ & $1.47 \%[22]$ & $0.64 \%[22]$ & $0.2 \%[22]$ \\
Obesity/overweight & $27.45 \%[14][16]$ & $20.5 \%[12]$ & $24.1 \%[10][15]$ & $9.3 \%[18]$ & $25 \%[22]$ \\
Hypertension & $30.5 \%[14]$ & $7 \%[19]$ & $9.8 \%[10][15]$ & $26.7 \%[18]$ & $25 \%[22]$ \\
Diabetes & $4.3 \%[15]$ & $2 \%[20]$ & $2.2 \%[10][15]$ & $1 \%[18]$ & $8 \%[22]$ \\
\hline
\end{tabular}

The rate of cancer in university students is similar in Europe and North America, no significant difference was seen between these two regions. The Caribbean had the lowest cancer rate (0.2) followed by Africa (0.6\%) and Asia (1.47\%). A Significant difference in cancer rate was seen between Africa and Europe and Asia and Europe $(P<0.05)$.

Showing the associated risk factors of each lifestyle disease reviewed.

\begin{tabular}{|c|c|}
\hline Lifestyle Diseases & Associated Risk Factors \\
\hline Obesity/Overweight & $\begin{array}{l}\text { Poor diet (high in fat and protein but low in dietary fiber } \\
\text { and carbohydrate), little or no exercise, } \\
\text { smoking \& family history of the disease [8] [9] [10]. }\end{array}$ \\
\hline $\begin{array}{l}\text { Hypertension/Cardiovascular } \\
\text { Disease }\end{array}$ & $\begin{array}{l}\text { Smoking, Lack of exercise, family history of the } \\
\text { disease and diet high in fat [8] [9] [19]. }\end{array}$ \\
\hline Diabetes & $\begin{array}{l}\text { Diet high in sugar and fat, lack of exercise, } \\
\text { family history of the disease [18] [20]. }\end{array}$ \\
\hline Cancer & $\begin{array}{l}\text { Diet lacking fruits and vegetables, obesity, } \\
\text { family history of the disease lack of physical activities [21]. }\end{array}$ \\
\hline
\end{tabular}




\section{References}

[1] World Health Organization (2014) Non Communicable Diseases Facts Sheet. http://www.who.int/mediacentre/factsheet/fs355/en/

[2] Cadwell, A. (2012) "Lifestyle" Diseases the World Biggest Killer. http://mobile.abc.net.au/news/2011-04-28/lifestyle-diseases-the-worlds-biggest-kille $\underline{\mathrm{r} / 2695712}$

[3] Alwan, A. (2010) Global Status Report on Non-Communicable Diseases. 1-176. http://www.who.int/nmh/publications/ncd_report_full_en.pdf

[4] World Health Organization (2014) Obesity Factsheet. http://www.who.int/mediacentre/factsheets/fs311/en/\#

[5] World Health Organization (2014) Cardiovascular Disease. http://www.who.int/topics/cardiovascular_diseases/en/

[6] World Health Organization (2014) Diabetes Fact Sheet. http://www.who.int/topics/diabetes_mellitus/en/

[7] The Global Burden of Chronic Diseases. http://www.who.int/nutrition/topics/2_background/en/

[8] Costa Silva Zemdeg, J., et al. (2011) Lipid Profile and Cardiovascular Risk among First Year Brazilian University Students in SAO Paulo. Nutricion Hospitalaria, 26, 553-559. http://scielo.isciii.es/pdf/nh/v26n3/18_original_14.pdf

[9] Palomoa, I., Torresb, G., Alarcóna, M., Maragañoc, P., Leivaa, E. and Mujicac, V. (2006) High Prevalence of Classic Cardiovascular Risk Factors in a Population of University Students from South Central Chile. Revista Española de Cardiología, 59, 1099-1105.

[10] Stack, J., Mahoney, S. and Christopher, H. (2014) Factors Associated with Diabetes Risk in South Texas College Students. International Journal of Exercise Science, 7, Article 2. http://digitalcommons.wku.edu/ijes/vol7/iss2/2

[11] Al-Majed, H.T. and Sadek, A. (2012) Pre-Hypertension and Hypertension in College Students in Kuwait: A Neglected Issue. Journal of Family and Community Medicine, 19, 105-112. https://doi.org/10.4103/2230-8229.98296

[12] Bai, P.V., et al. (1995) Prevalence of Diabetes in the Young in South India. Indian Pediatrics, 32, 1173-1176. http://www.ncbi.nlm.nih.gov/pubmed/8772865

[13] Musaiger, A.O., Lloyd, O.L., Al-Neyadi, S.M. and Bener, A.B. (2003) Lifestyle Factors Associated with Obesity among Male University Students in the United Arab Emirates. Nutrition \& Food Science, 33, 145-147. https://doi.org/10.1108/00346650310488480

[14] Nojomi, M. and Najamabadi, S. (2006) Health Promoting Lifestyle and its Determinants Among University Students in Sabzevar, Iran. Asia Pacific Journal of Clinical Nutrition, 15, 516-520.

[15] Huang, T., Harris, K., Lee, R., Nazir, N., Born, W. and Kaur, H. (2003) Assessing Overweight, Obesity, Diet, and Physical Activity in College Students. Journal of American College Health, 52.

[16] AI-Isa, A.N. (1999) Obesity among Kuwait University Students: An Explorative Study Perspectives. Public Health, 119, 223-227.

[17] Lima, V., Cavalieri, G., Lima, M., Nazario, N. and Lima, G. (2014) Risk Factors for Type 2 Diabetes Mellitus in College Students: Association with Sociodemographic Variables. The Revista Latino-Americana de Enfermagem, 22.

http://www.scielo.br/scielo.php?script=sci_arttext\&pid=S0104-11692014000300484 \&Ing=en\&nrm=iso\&ting $=$ en 
[18] Northwestern University (2014) College Kids Need to Change Unhealthy Ways. ScienceDaily, May 6. www.sciencedaily.com/releases/2014/05/140506161304.htm

[19] University of the Sciences (2013) Lifestyle Factors Could Put College-Age Women at Higher Risk of Breast Cancer. ScienceDaily, October 21. www.sciencedaily.com/releases/2013/10/131021211452.htm

[20] American Diabetes Association (2014) Statistics about Diabetes. http://www.diabetes.org/diabetes-basics/statistics/

[21] Simãoetal (2008) Hypertension among Undergraduate Students from Lubango, Angola. The Revista Latino-Americana de Enfermagem, 16. http://www.scielo.br/scielo.php?script=sci_arttext\&pid=S0104-11692008000400004

[22] World Health Organization (2014) Global Status Report on Non Communicable Diseases Facts.

http://www.who.int/iris/bitstream/10665/148114/1/9789241564854_eng.pdf

Submit or recommend next manuscript to SCIRP and we will provide best service for you:

Accepting pre-submission inquiries through Email, Facebook, LinkedIn, Twitter, etc. A wide selection of journals (inclusive of 9 subjects, more than 200 journals)

Providing 24-hour high-quality service

User-friendly online submission system

Fair and swift peer-review system

Efficient typesetting and proofreading procedure

Display of the result of downloads and visits, as well as the number of cited articles Maximum dissemination of your research work

Submit your manuscript at: http://papersubmission.scirp.org/

Or contact ijcm@scirp.org 